\title{
Teknologi Informasi Geografi Untuk Pembangunan Nasional dan Mitigasi Bencana di Era Global
}

\author{
Hartono \\ Universitas Gadjah Mada \\ Email: hartono.geografi@ugm.ac.id
}

\begin{abstract}
Abstrak - Geografi sebagai cabang ilmu yang sudah mapan, dengan obyek kajiannya berupa bumi dan langit, memiliki berbagai peran nyata dalam membangun peradaban bangsa. Peran geografi tersebut antara lain sebagai salah unsur pembentuk negara, mendukung ketahanan nasional (pangan, energi, geopolitik...), mengkaji keberadaan sumberdaya alam, manusia dan buatan, mendukung perencanaan, implementasi, monitoring dan evaluasi pelaksanaan pembangunan nasional, menumbuhkan rasa cinta tanah air dan mitigasi bencana. ISO TC 211 menegaskan bahwa Teknologi Informasi Geografi (TIG), yang meliputi Kartografi, Penginderaan Jauh, SIG, GPS, dan Visualisasi semakin berkembang dalam hal teknik dan aplikasinya dalam mendukung pembangunan nasional dan mitigasi bencana. Di Indonesia, pembangunan nasional selalu melibatkan ruang sebagai obyek pembangunannya, dimana penataan ruang sangat penting untuk menjamin keberlangsungan dan kelestarian negeri ini. Bencana alam hampir merupakan agenda tahunan baik berupa longsorlahan, banjir, kekeringan, kebakaran hutan, dan bencana lainnya (tsunami, gempa bumi). Berbagai aktivitas dalam mitigasi bencana memerlukan data dan informasi tentang kejadian dan penyebabnya. Inisiasi pemulihan lingkungan yang mengalami kerusakan memerlukan data geospasial yang dikelola dengan dalam TIG. Bentuk aplikasi geografi dalam pembangunan antara lain inventarisasi, pemetaan dan survei data tentang potensi sumberdaya alam dan bencana alam, pembentukan basisdata dan sistem informasi sumberdaya alam dan kebencanaan, analisis, sintesis, pemantauan, dan evaluasi proses dan hasil pembangunan. Dalam kebencanaan dapat disusun sistem peramalan dini dan system penentu kebijakan. Menuju kelestarian lingkungan dan pemanfaatan sumberdaya, konsep brown, green, dan blue economy, yang bertumpu pada pemanfaatan resources, perlu diintrodusir dan diterapkan dengan baik, agar tercappai kelestarian alam dan dapat mensejahterakan rakyat. Geograf dengan kemampuan kecerdasan spasial, mampu melakukan inventarisasi, pemetaan dan survei data untuk pembangunan nasional dan mitigasi bencana. Hasil kegiatan tersebut disajikan dalam basisdata spasial pembangunan dan sistem informasi kebencanaan yang bermanfaat untuk pembangunan nasional dan mitigasi bencana. Sistem informasi bencana dapat mendukung sistem peramalan dini dan sistem penentu kebijakan (Early Warning and Decision Support Systems).
\end{abstract}

Kata kunci:Geografi, Mitigasi Bencana, Pembangunan Nasional

\section{PENDAHULUAN}

Banyak problema bangsa ini yang belum beranjak dari hal-hal mendasar yang selama enam puluh tahun terakhir ini belum mampu kita pecahkan. Problema tersebut antara lain masalah kemiskinan, pengangguran kentara dan tak kentara, jurang kesejahteraan masyarakat yang makin lebar, kualitas sumberdaya manusia, ekploitasi sumberdaya alam yang kurang proporsional, ketahanan pangan, kedaulatan politik, kemandirian ekonomi, hak azasi manusia, degradasi lahan dan bencana alam yang tiada henti dan diperparah dengan masalah korupsi yang menggurita. Dalam pandangan geografi, problema terkait ruang (sumberdaya alam, mitigasi bencana, degradasi lingkungan, batas wilayah dan negara, alih fungsi lahan) perlu memperoleh perhatian yang serius, mengingat bahwa hal-hal tersebut menyangkut hajat hidup rakyat yang perlu diprioritaskan.

Untuk pengelolaan sumberdaya alam, pasal 33 UUD 1945 ayat 3 dengan jelas menyatakan bahwa bumi dan air dan kekayaan alam yang terkandung di dalamnya dikuasai oleh negara dan dipergunakan untuk sebesar-besar kemakmuran rakyat. Pengelolaan sumberdaya alam (SDA) memiliki pengertian terciptanya kelestarian alam dengan melaksanakan pembangunan berkelanjutan (sustainable development). Otonomi daerah, yang diatur dalam UU 32/2004, memiliki dimensi administratif sedang SDA berdimensi ekologis (lingkungan), kedua batasan tersebut sering tidak selalu berimpit. Pemberdayaan SDA bagi kesejahteraan rakyat dan bagi pelaksanaan otonomi daerah, memerlukan data dan informasi geospasial SDA pada berbagai jenjang kerincian dari jenjang makro hingga jenjang mikro, dari skala 1:1.000.000 hingga skala 1:1.000. Hal terakhir ini telah diatur dalam UU 4/2011. Pengelolaan data dan informasi geospasial dapat terselenggara berkat peranan penting teknologi informasi geografi (penginderaan jauh, system informasi geografi, GPS, kartografi, dll). Pengembangan geodatabase yang handal mmenjamin terfasilitasinya berbagai program pemangunan nasional, pada tahap perencanaan hingga evaluasi.

Strategi dan kebijakan dalam otonomi daerah meliputi (1) Aspek Kelembagaan, (2) Aspek Sumberdaya Manusia, (3) Aspek Perencanaan, (4) Aspek keuangan daerah, (5) Aspek Logistik (sarana dan prasarana), (6) Aspek Hukum, (7) Aspek Konflik. Aspek SDM memegang kunci penting dalam pengelolaan SDA yang terdapat di kabupaten tersebut. Katili, (1983), menyatakan bahwa SDA meliputi sumberdaya tanah, lahan, air, energi, mineral-mineral non 
energi,hutan, perikanan, laut yang Lain, dan lingkungan. Bakosurtanal, (1995), dalam kegiatannya di bidang neraca sumberdaya alam merinci potensi SDA ke dalam empat macam yaitu hutan, lahan, air, dan mineral batuan. Unsur laut dan sumberdaya yang terkandung didalamnya, yang telah dideklarasikan oleh Djuanda Kartawijaya pada 13 Desember 1957, tentang negara kepulauan, masih perlu diperjuangkan agar makin mmemperoleh porsi pengelolaan yang memadai. Pemerintahan Gus Dur telah membangun Kementerian Kelautan dan Perikanan (KKP), yang menandai era menuju negara bahari yang makin mantap. Hal ini dipertegas oleh kepemimpinan Dr. Fadel Muhammad di KKP, yang mencanangkan untuk menjadi negara penghasil ikan terbesar di dunia, yang memang hal tersebut realistik. Hal ini ke depan perlu mendapatkan prioritas pembangunan, selagi banyak wilayah daratan yang mengalami degradasi, baik oleh bencana alam maupun oleh ulah manusia.

Era global dicirikan dengan kemajuan teknologi bidang informasi dan komunikasi yang mewarnai segalla segi kehidupan dan peradapan manusia. Kemajuan teknologi ICT telah menyebabkan negara tanpa batas, karena informasi dengan cepat dan mudah diakses, sehingga kepiawaian mengelola informasi akan menjadikan suatu bangsa menjadi leading dalam berbagai segi kehidupan. Dalam hal aplikasi ilmu geografi, ICT telah menjadikan terapan konsep dalam geogafi menjadi nyata. Tampilan 2, 3 dan 4 dimensi obyek geografi menjadikan imu ini makin nampak manfaat pentingnya dalam berbagai program pembangunan nacional, baik dalam pengembangan wilayah maupun dalam pengelolaan wilayah akibat bencana.

Otonomi daerah memungkinkan daerah untuk mengelola SDA, secara mandiri berdasarkan aspirasi rakyat. Pengelolaan SDA sebaiknya mengacu pada kelestarian alam dengan melaksanakan pembangunan berkelanjutan (sustainable development). Pemanfaatan SDA jangan hanya bertumpu pada kepentingan manusia (antropocentris) dengan memacu pendapatan, karena dapat menimbulkan pemanfaatan yang berlebihan. Otonomi daerah berdimensi administratif (kabupaten/kotamadya), sedang SDA berdimensi ekologis (lingkungan), kedua batasan tersebut tidak selalu berimpit. Pendekatan sustainable development nampaknya lebih sesuai dengan otonomi daerah yaitu memerlukan keseimbangan antara nilai ekonomis dan nilai ekologis, dengan kata lain memanfaatkan SDA sebaikbaiknya dengan tetap menjaga kelestarian lingkungannya.

Eksploitasi yang berlebihan dapat menyebabkan timbulnya bencana alam dan kerusakan DAS, seperti banjir, kekeringan, lahan longsor, kebakaran hutan, dan bencana lainnya. Dewasa ini bencana tersebut sering terjadi. Lingkungan darat, dalam lingkup Daerah Aliran Sungai (DAS) mengalami penurunan kualitas, sedang lingkungan laut masih dianggap sebagai tempat buangan limbah dan sampah. Fakta adanya degradasi lahan di darat, menyebabkan perhatian perlu ditingkatkan terhadap pengembangan wilayah di darat dan juga di laut, yang selama ini belum terperhatikan dengan maksimal. Hampir setiap tahun Indonesia memperoleh citra kurang baik dari negara-negara tetangga di ASEAN, disebabkan oleh adanya kebakaran hutan, di Kalimantan dan Sumatra. Asap yang ditimbulkan terbawa angin hingga menerpa wilayah Singapura dan Malaisia, dan hal tersebut mengganggu transportasi udara dan kehidupan sehari-hari.

Kajian bencana alam memerlukan data dan informasi pada berbagai jenjang kerincian. Pada tingkat kabupaten, informasi pada tingkat semidetil dan detil diperlukan untuk penyusunan rencana penanganan (management plan), action plan dan rancangan teknisnya. Informasi bencana alam yang tersedia belum mampu memenuhi kualifikasi tersebut. Untuk itu perlu usaha pendetilan informasi melalui berbagai teknik survai baik secara terestrial, maupun dengan penginderaan jauh, pemotretan skala besar (gantole, ultralight), satelit resolusi halus (IKONOS 1,5 m) dan teknik lain. Pada area yang lebih luas (propinsi, negara, kawasan regional) penggunaan teknologi satelit (NOAA, Landsat, SPOT, ERS-1, MOS) lebih sesuai, dilihat dari kemampuan spasial, spektral, temporal dan cakupan datanya (10-30m, visible, inframerah, microwave, 16 hari). Hasil yang diberikan pada skala makro. Pada tujuan yang lebih sempit dan detil, diperlukan data yang berskala lebih besar. Teknologi penginderaan jauh selain bermanfaat bagi identifikasi, pemetaan dan pantauan terjadinya bencana alam, juga dapat berfungsi sebagai masukan pada pembentukan sistem informasi kebencanaan.

Hal-hal tersebut di atas menunjukan bahwa berbagai problema bangsa, pengelolaan SDA dan LH yang lestari, peran teknologi informasi geografi, otonomi daerah, mitigasi bencana, kesemuanya berkaitan erat dengan bidang geografi, terutama perlunya penerapan konsep, pendekatan dan aplikasi geografi dalam penyelesaian berbagai problema tersebut. Pemanfaatan ruang, eksploitasi SDA dan LH, sistem informasi geografi dan pemanfaatan serta aplikasi data dan informasi sumberdaya sangat penting untuk digunakan dalam berbagai tahap pembangunan agar dicapai hasil yang lestari. Paper ini membincangkan peran Teknologi Informasi Geografi dalam pembangunan nacional dan mitigasi bencana di era global.

\section{GEOGRAFI DAN TEKNOLOGI INFORMASI GEOGRAFI}

A. Konsep dan Pendekatan Geografi

Geografi merupakan ilmu yang mempelajari tentang bumi dan hubungannya dengan kehidupan manusia. Ilmu pendukung geografi antara lain meliputi hidrologi, geomorfologi, pedologi, geografi kota, desa, dan didukung oleh teknologi informasi geografi. Manusia pada mulanya tergantung danmenyesuaikan dengan alam (deterministik), sehingga terbentuk pola peradaban manusia yang dicirikan oleh karakteristik fisik alam. Lambat laun manusia memegang peranan, terutama dengan dikuasainya teknologi, sehingga manusia mengatur alam untuk memenuhi kesejahteraannya (positivism). Daerah yang tidak memiliki sumberdaya air tawar, manusia mampu mendestilasi air laut untuk menghasilkan air minum dan kebutuhan domestik lainnya (di pulau-pulau terpencil).

Hagget (1978) menyebutkan bahwa geografi memiliki tiga pisau análisis dalam pendekatannya untuk mempelajari 
fenomena bumi, yaitu pendekatan ekologik, spasial dan wilayah. Ketiga pendekatan tersebut secara nyata telahh diterapkan dalam pembangunan nacional, dan memberikan hasil yang baik. Dalam berbagai fakta, sering pemengelola wilayah lupa dan tidak menerapkan hampiran geografi tersebut dengan konsekuan, akibatnya banyak dijumpai kerusakan lahan, degradasi lingkungan, dsb. Daya dukung wilayah cenderung diabaikan, sehingga prinsip ekologik belum digunakan dengan baik.

Masalah geografi yang kini perlu percepatan penyelessaian antara lain adalah kadaster laut, pemberian toponimie bagi 17508 pulau kita yang belum semuanya selesai, penataan tataguna tanah, hak atas lahan, penataan batas wilayah nacional maupun internacional, rehabilitasi kerusakan lingkungan. Pendataan pulau baru mencapai 13466, itupun belum sempurna. Hal-hal tersebut adalah contoh persoalan spasial dan wilayah, yang masih sangat diperlukan di Indonesia.

Kajian dan análisis geografi menjadi makin menguat antara lain dengan digunakannya análisis kualitatif, kuantitatif, statistik dan SIG. Peran penting geografi dikuatkan oleh SIG, yang dengan jelas dinyatakan oleh Dangermond, (2011) the role of geography is a platform for understanding the world. GIS is making geography come alive. It condenses our data, information, and science into a language that we can easily understand: maps. Aplikasi geografi mencakup berbagai bidang pembangunan (pertanian, kehutanan, kesehatan terkait lingkungan, industry, jasa, pendidikan, dll)

\section{B. Teknologi Informasi Geografi}

Dalam kaidah standart internasional, informasi geografi telah diatur dalam Geographic Information/Geomatics, tertuang dalam ISO/TC $211 \mathrm{~N}$ 573. Dalam ketentuan tersebut, informasi geografi didukung dengan 10 buah teknologi berikut : (1) Digital survey instruments, (2) Global Positioning System, (3) Remote Sensing, (4) Geographic Information Systems, (5) Spatial Systems Engineering Tools, (6) Spatial Database Management, (7) Automated Cartography, (8) Visualisation, (9) Modeling, (10) Spatial Analysis. Pengelolaan informasi geospasial untuk kajian dan deliveri informasi bidang geografi, lingkungan, wilayah dan bencana perlu didukung dengan system penyedia data yang berkelanjutan, dalam hal ini adalah teknologi penginderaan jauh, SIG dan GPS, maupun teknologi pendukung geographic information yang lain. Berikut diuraikan 2 teknologi yang telah dikembangkan oleh lembaga-lembaga pendidikan Geografi di Indonesia : Penginderaan Jauh dan SIG, dimana SIG sebagai sistem telah berkembang pesat menjadi Sains Informasi Geografi.

\section{Penginderaan Jauh}

Dalam memilih sistem penginderaan jauh yang sesuai dengan tujuan penerapannya, maka perlu memahami konsep resolusi. Resolusi sangat menentukan tingkat kerincian obyek, sifat signatur spektral, periode ulang untuk monitoring dan tampilan datanya, yang terdiri dari empat resolusi, yaitu : (a) Resolusi spektral, (b) Resolusi spasial, (c) Resolusi temporal, dan (d) Resolusi radiometrik. Resolusi spasial mencerminkan rincian data tentang obyek yang dapat disadap dari suatu sistem penginderaan jauh, dalam bentuk ukuran obyek terkecil yang dapat disajikan, dibedakan, dan dikenali pada citra, disebut pixel (picture element). Resolusi spektral menunjukkan kerincian spektrum elektromagnetik yang digunakan dalam suatu sistem penginderaan jauh. Resolusi temporal merupakan frekuensi perekaman ulang bagi daerah yang sama oleh suatu sistem penginderaan jauh, dan resolusi radiometrik menunjukkan kepekaan suatu sistem sensor terhadap perbedaan terkecil kekuatan sinyal yang sampai pada sensor tersebut.

Para interpreter telah terbiasa dengan pengenalan hasil pemotretan tegak yang dihasilkan (foto udara). Foto udara makin terkenal ketika digunakan dalam Perang Dunia I, untuk merekam pergerakan lawan. Foto udara menyajikan gambar yang jelas, mudah ditafsirkan dan bermanfaat untuk kajian yang berkaitan dengan muka bumi. Berdasarkan jenis film yang digunakan, foto udara dibedakan manjadi foto udara pankromatik, inframerah, ultra violet dan ortrokromatik. Penginderaan dengan cara ini bersifat manual, baik sistem, data dan cara interpretasinya. Sistem hyperspektral (CASI, The MAP), memunculkan fenomena baru dalam penginderaan ini, karena sifat spektral obyek dapat dicermati menjadi lebih rinci. Small format photography berskala 1:5000 atau lebih besar, biaya relatih murah (Rp.200.000,-/Ha), menawarkan produk lain yang lebih kompetitif pada era otonomi daerah ini.

Penginderaan jauh satelit menggunakan satelit sebagai kendaraan untuk membawa sensor dalam rangka penginderaan bumi pada ketinggian ratusan hingga ribuan kilometer. Penginderaan dengan satelit bersifat otomatik dengan sistem orbit sunsynchronous : pemotretan teratur, pengiriman data secara elektronik, analisis data secara digital. Jenis satelit yang digunakan untuk inventarisasi dan evaluasi dinamika bumi misalnya adalah Landsat (Multispektral Scanner, Thematic Mapper), System Pour l'Observation de la Terre (SPOT), Marine Observation Satelite (MOS), National Oceanic and Atmospheric Administration (NOAA), Geometeorological Satellite (GMS), Barkara, ERS-1, JERS-1, ALMAZ-1, IRS, ADEOS. Contoh citra Penginderaan Jauh disajikan pada gambar 2.

\section{Sains Informasi Geografi}

DeMers (1997) menyatakan bahwa SIG adalah seperangkat alat yang memungkinkan kita untuk mengolah data spasial menjadi informasi yang berkaitan dan digunakan untuk membuat kebijakan entang muka bumi. Aronoff (1989) memberikan pengertian SIG sebagai suatu sistem berbasis komputer yang memiliki 4 kemampuan untuk menangani data spasial : pemasukan, pengelolaan data (penyimpanan dan pengaktifan kembali), manipulasi dan analisis, serta keluaran (output). Parent (1988, dalam Antenucci et al., 1991) menekankan aspek kemampuan GIS untuk menghasilkan informasi baru, dengan membatasinya sebagai suatu sistem yang memuat data dengan rujukan spasial, yang dapat dianalisis dan dikonversi menjadi 
informasi untuk keperluan tertentu. Parent (1988) menegaskan bahwa kemampuan penting suatu SIG adalah analisis data untuk menghasilkan informasi baru.

Kekuatan dari SIG adalah terbentuknya new spatial information dari hasil analisis basisdata, melalui berbagai proses yang dapat dilakukan pada SIG , melalui (1) Pemrosesan data atribut (Query dan Kalkulasi), (2) Pemrosesan data grafis (mengubah skala, mengubah Sistem Proyeksi, Rotasi dan Translasi, Pengkondisian (Spasial Querying), Tumpangsusun (Overlay), Re-klasifikasi, Jarak dan Buffer, model Elevasi/Medan Digital, pemodelan Spasial dan Kalkulasi Data Grafis); dan (3) Terpadu antara data grafis dan atribut (Pengkaitan atribut ke grafis dengan simbol area, warna, angka, diagram).

Kajian dan análisis geografi, dengan mmenggunakan data geospasial makin menguat dengan digunakannya análisis kualitatif, kuantitatif, statistik dan Sistem Informasi Geografi. Peran penting geografi dikuatkan oleh SIG, yang dengan jelas dinyatakan oleh Dangermond, (2011) the role of geography is a platform for understanding the world. GIS is making geography come alive. It condenses our data, information, and science into a language that we can easily understand: maps.

Perkembangan keilmuan SIG telah merubah SIG sebagai system menjadi SIG sebagai sains. Kenyataan tersebut ditegaskan oleh Goodchild (2004) dan juga termuat dalam Wikipedia (2016) sbb : Geographic information science or Geographical information science (GIScience) is the scientific discipline that studies data structures and computational techniques to capture, represent, process, and analyze geographic information. It can be contrasted with geographic information systems, which are software tools. British geographer Michael Goodchild has defined this area in the 1990s, and summarized its core interests, including spatial analysis, visualization, and the representation of uncertainty. GIScience is conceptually related to geography, information science, computer science, geomatics and geoinformatics, but it claims the status of an independent scientific discipline. SIG sebagai sains didukung oleh teknologi Penginderaan Jauh, SIG sebagai system dan GPS.

Aplikasi geografi mencakup berbagai bidang pembangunan (pertanian, perkebunan, kehutanan, kesehatan terkait lingkungan, industry, jasa, pendidikan, bencana dll) Dalam era global, diperlukan data geospasial yang lengkap, baru, akurat dan pengelolaan data dan informasi yang mudah diakses. Teknik penginderaan jauh dan SIG dapat memberikan solusi tentang pengelolaan data dan informasi geografi (air, tanah, iklim, penggunaan lahan, infrastruktur, transportasi, batas wilayah pengelolaan, kejadian dan dampak bencana, dll).

Tatakelola informasi geospasial diatur dalam UU 4 tahun 2011, yang diikuti dengan peraturan implementatif di bawahnya, yang memperjelas tahapan operasionalnya. PP $10 / 2000$ mengatur tentang ketelitian peta tematik pendukung tata ruang. Keppres 85/2007 mengatur tentang Jaring data Spasial Nasional, lembaga mana memproduksi peta apa. Berbagai SNI telah diterbitkan, untuk memberikan panduan tentang kompetensi dan spesifikasi produk spasial tertentu. Pemanfaatan data geospasial untuk terapan pengelolaan SDA dan LH mencakup $5 \mathrm{M}$ (measurement, mapping, monitoring, modeling, dan management). UU 32 tahun 2009, menjelaskan bahwa pengelolaan mencakup 6 kegiatan

perencanaan, pemanfaatan, pengendalian, hingga penegakan hukum. Data geospasial mestinya mampu digunakan sebagai bukti penegakan hukum pengelolaan sumberdaya alam dan lingkungan hidup yang tidak sesuai dengan prinsip kelestarian (sustainability.

\section{Sosialisasi dan Diseminasi Data Geospasial}

Basisdata yang telah dibangun dalam sistem informasi geospasial perlu disosialisasikan dan didistribusikan kepada pada user terkait pembangunan dan bencana, agar dapat dimanfaatkan secara efektif. Hal ini dapat dilakukan dengan teknologi informasi, memanfaatkan internet, radio, media massa cetak dan elektronik. Dengan demikian maka pembangunan nasional dan penanganan bencana alam menjadi lebih baik. Database kebumian yang telah tersedia di Kimpraswil, LAPAN, BAKOSURTANAL, INTAG, BAKORNAS, perlu dimasyarakatkan. Real-networking perlu digalakan, baik dalam sharing data, expertise, kerjasama, bagi berbagai kepentingan sipil, termasuk bencana alam. BIG telah membangun sebuah portal dengan nama InaGeoportal, yang menampung data spasial dasar dan tematik dari seluruh kementerian, yang terbuka untuk umum untuk dimanfaatkan. Portal ini memungkinkan penyusunan peta oleh para user sendiri sesuai tujuannya. Download data dan informasi pada portal tersebut dapat dilakukan melalui http://tanahair.indonesia.go.id/home

\section{Informasi Geospasial}

Dalam era pembangunan dan globalisasi, diperlukan data geospasial yang lengkap, baru, akurat dan pengelolaan data dan informasi yang mudah diakses. Dalam hal ini, teknik penginderaan jauh dan SIG dapat memberikan solusi tentang data dan imformasi obyek geografi, baik lithosfer, hidrosfer, atmosfer, biosfer, dan antroposfer. Teknologi penginderaan jauh, melalui produk yang dihasilkan (citra foto, citra satelit) dapat dimanfaatkan sebagai sumberdata obyek geografi maupun informasi lingkungan, baik lingkungan abiotik (sumberdaya alam), lingkungan biotik (flora dan fauna), serta lingkungan budaya (bentuk penggunaan lahan dan semua hasil budidaya manusia). Data dan informasi geospasial dapat berupa peta dasar, peta tematik, citra foto udara, citra satelit, chart, denah, maket, sistem informasi spasial, baik yang statik maupun dinamik. Teknologi pengelolaan informasi geospasial memanfaatkan teknologi ICT dengan intens, sehingga bidang kajian geografi tidak hanya meliputi geografi fisik dan geografi manusia, tetapi juga didukung oleh teknologi informasi geografi, yang menjadikan kajian geografi makin bermakna.

Data dan informasi geospasial dapat diperoleh secara langsung melalui teknik pengukuran, sensus ataupun observasi, sesuai dengan tujuan perolehannya. Pengolahan citra penginderaan jauh, dapat dimanfaatkan untuk berbagai aplikasi, terutama dalam bidang SDA dan LH. Manfaat tersebut antara lain perolehan data dan informasi tentang 
jenis, luas, distribusi, dan kualitas SDA dan LH secara cepat dan perubahan-perubahannya. Teknik penginderaan jauh memerlukan tenaga dan pelaksana yang mampu mengelola citra : interpretasi citra hingga menyajikannya ke dalam bentuk peta sumberdaya atau produk digital lainnya. Produk tersebut kemudian dapat digunakan sebagai input dalam penyusunan basisdata wilayah, yang bermanfaat utk berbagai keperluan pengelolaan wilayah.

Tatakelola informasi geospasial diatur dalam UU 4/2011, yang diikuti dengan peraturan implementatif di bawahnya, yang memperjelas tahapan operasionalnya. PP 10/2000 mengatur tentang ketelitian peta tematik pendukung tata ruang. Keppres 85/2007 mengatur tentang Jaring data Spasial Nasional, lembaga mana mmemproduksi peta apa. Bberbagai SNI telah diterbitkan, untuk memberikan panduan tentang kompetensi dan spesifikasi produk spasial tertentu (Panduan penyusunan Peta Rupa Bumi, dll).

\section{PERAN TEKNOLOGI INFORMASI GEOGRAFI UNTUK PEMBANGUNAN NASIONAL}

Program pembangunan nasional tahun 2000, tercantum dalam UU No. 25 tahun 2000, bab X memuat Program Pengembangan dan Peningkatan Akses Informasi sumberdaya alam (SDA) dan Lingkungan Hidup (LH). Butir-butir rincian dalam UU tersebut dapat digunakan sebagai dasar untuk menunjukan manfaat geografi dan informasi geospasial. Program tersebut berisi perlunya :

1. Inventarisasi dan evaluasi potensi SDA dan lingkungan hidup (LH), yang meliputi darat, laut, udara

2. Valuasi potensi sumberdaya hutan, air, laut, udara dan mineral, yang memungkinkan semua sumberdaya memiliki harkat, yang bermanfaat bagi pelaksanaan UU 4/1982, tentang lingkungan hidup

3. Pengkajian neraca sumberdaya alam, baik spasial maupun numerik

4. Penyusunan produk domestik bruto hijau secara bertahap

5. Pendataan kawasan ekosistem yang rentan terhadap kerusakan, termasuk wilayah kepulauan

6. Pendataan batas kawasan hutan, pengkajian IPTEK bidang sistem informasi sumberdaya alam dan lingkungan hidup

7. Peningkatan akses informasi SDA dan LH kepada masyarakat, stake holders.

Buti-butir tersebut dengan jelas mewajibkan pada semua geospasial data provider untuk mengembangkan sisem informasi geografi, yang dapat memberikan layanan kepada masyarakat secara real time dan menyeluruh. Agar supaya suatu lembaga dapat melaksanakan kegiatan pengelolaan wilayah untuk pembangunan dan menanggulangi bencana, maka sebuah institusi pengelolaan data geospasial amat diperlukan. Penyusunan institusi tersebut memerlukan tersedianya hardware, software, data spasial dan numerik, sumberdaya manusia, prosedur kerja standart, dan mekanisme pendukung. Pengembangan institusi semacam ini memerlukan pemantapan tujuan, dukungan dana, sumberdaya manusia (teknisi, analis, pengelola), spasial information expert, application GIS expert dan perlu berhubungan dengan para vendor. Manfaat TIG dan data/informasi geografi dalam pembangunan nasional, antara lain dapat diuraikan dalam 11 butir aplikasi berikut.

\section{A. Penyusunan Basisdata Sumberdaya Alam}

Data dasar nasional berisi data dan informasi dasar geografis yang tercakup dalam peta Topografi, Rupabumi, lingkungan Pantai Indonesia, Lingkungan Laut Nasional dan Benua Maritim. Sebesar $70 \%$ dari wilayah nasional telah terselesaikan. Data tematik yang dibangun di atas data dasar meliputi tematik abiotik (geologi, tanah, air, iklim, mineral, laut), biotik (vegetasi) dan data sosial ekonomi penduduk. Perolehan data tersebut oleh instansi penghasil data (BPN, Puslittanak, Dirjen Geologi, Lemigas, Departemen Kehutanan, Bakosurtanal, Jawatan Topografi, Kimpraswil, BMG, BPS, Dirjen Pajak PBB) menggunakan data penginderaan jauh dan diolah dengan SIG. Pembentukan IDSN dan IDSD telah dimulai, monitoring kemajuan antar instansi penghasil dan pengguna data dilakukan melalui Rakor dan Rakortek SIG, yang berlangsung setiap tahun. PP 10/2000, mengatur tentang penyusunan Peta RTRW Nasional minimal 1 : 1.000.000; Peta RTRW Daerah Propinsi, minimal 1 : 250.000. Peta RTRW Daerah Kabupaten, minimal $1: 100.000$. Peta RTRW Daerah Kota, minimal 1 : 50.000. Data nasional sebagai input terbentuknya basisdata nasional telah tersedia dalam skala 1:1000.000 dan 1:250.000, sedang skala yang lebih besar masih perlu dikerjakan dengan cara-cara yang lebih sistematik.

\section{B. Kajian Sumberdaya Mineral dan Batuan}

Pemanfaatan SIG untuk pemetaan sumberdaya mineral dan batuan dapat dicontohkan dengan studi Asadi, H.H. (2000), berjudul The Zarshuran gold deposit model applied in a mineral exploration GIS in Iran. Sebuah disertasi doctor di Delft University of Technology. Enam model pendekatan telah dilakukan untuk melokalisir cebakan emas, dengan menggunakan data peta, citra satelit, citra aeromagnetic dan survey lapangan. Enam pendekatan tersebut adalah (1) Chemically-reactive host rocks (Precambrian shale, limestone), (2) Metal source rocks (serpentinized ophiolite), (3) Igneous heat sources (andesite, basalt), (4) Faults (trending NW-SE, E-W and NE-SW), (5) Hydrothermal alteration (argillic, iron oxide), (6) Geochemical signature (of orpiment, sphalerite and sulphosalts). Tampilan spasial komposit dari masing-masing model tersebut dapat menghasilkan alternative lokasi potensi cebakan emas. Di Indonesia, model semacam ini telah dilakukan pula oleh Sriyono (2010); Rusyidi (2011).

\section{Kajian Sumberdaya Air}

Pemetaan, monitoring dan modeling sumberdaya air telah dilakukan oleh beberapa peneliti di Indonesia. Kekeringan, menyusutnya volume air permukaan, pendangkalan danau dan rawa, telah dilaporkan dalam berbagai media. Kajian Rawa Biru oleh WWF dan Fakultas Geografi UGM 2003, menunjukan fenomena tersebut. 
Contoh kajian entang sumberdaya air tanah, telak dilakukan oleh Dulbahri 1994 memetakan sumberdaya air tanah di DAS Progro dengan menggunakan foto udara inframerah 1;30.000, peta tematik dan kerja lapangan. Analisis spasial holistic dengan overlay, dilakukan dengan menggunakan berbagai variable abiotik sebagai input (geologi, geomorfologi, tanah, dan liputan lahan) dan mampu menunjukan potensi akuifer.

\section{Kajian Sumberdaya Lahan}

Pemetaan dan evaluasi sumberdaya lahan telah dilakukan oleh Puslitanak secara operasional, menggunakan foto udara. Pada LREP kegiatan tersebut makin meningkat. Penggunaan lahan dan kerusakan lahan telah dilakukan oleh BPN, Departemen kehutanan dan Lingkungan Hidup. Citra Penginderaan Jauh yaitu foto udara skala 1:20.000 digunakan untuk penentuan unit pemetaan medan (terrain mapping unit) dalam pembuatan peta tanah skala menengah. Peta tanah tersebut sebagai input penting dalam penyusunan peta kemampuan tanah, mengacu FAO (1976) dan peta kesesuaian lahan. Hingga kini telah diselesaikan pembuatan peta kesesuaian lahan untuk $>10$ buah komoditi, tanaman pangan dan tanaman perdagangan.

\section{E. Kajian Sumberdaya Hutan}

Kajian sumberdaya hutan dengan menggunakan SIG telah dilaksanakan dengan berbagai pendekatan baik multi spasial, spectral dan temporal. Serangkaian data dan informasi seri, multi level dan multi temporal telah dilakukan. Pemodelan dan prediksi kondisi hutan di masa depan telah mampu disajikan.

Fakta menunjukan bahwa hutan berkurang $>1$ juta $\mathrm{Ha}$ per tahun, melalui penebangan resmi maupun yang tidak resmi. Peta vegetasi Indonesia dari hasil teknologi satelit dan SIG misalnya ditunjukan dengan peta Yves Laumonier (1986), NFI (1991), JAFTA (1990), dengan menggunakan pendekatan ekofloristik, serta Agus Siswanto (2008) dengan metode berlapis. Monitoring luas hutan di Indonesia menggunakan citra satelit Landsat, selama 20 tahun terakhir, telah dilakukan oleh Belinda Arunarwati, staf peneliti Lapan.

\section{F. Kajian Sumberdaya Laut}

Kajian sumberdaya laut oleh Barmawi (2002) dengan menggunakan citra CASI hyperspektral mampu memetakan terumbu karang di Kepulauan Seribu. Citra MODIS telah digunakan untuk studi eutrofikasi perairan Teluk Jakarta oleh Sam Wouthuysen, 2004, tingkat eutrofikasi multiwaktu dapat disajikan.

Ekosistem laut Indonesia sangat kaya dengan sumberdaya hayati dan non hayati. Ekosistem mangrove, terumbu karang, padang lamun mendukung keberadaan ikan pelagis, demersal dan ikan jeluk yang banyak jumlahnya. Luas ekosistem terumbu karang sebesar $50.875 \mathrm{Km} 2$ (Burke, dkk, 2002). Sebesar 10-50\% ekosistem tersebut mengalami peningkatan degradasi karena berbagai sebab alami dan eksploitasi. Jumlah spesies adalah 574 buah (Vernon, dkk, 2009), sebesar 22,05\% terlindungi
(Kementerian Kehutanan). Ekosistem ini berada pada 1133 lokasi, dengan kondisi sangat baik 5\%; baik 27\%; cukup $37 \%$ dan buruk $31 \%$ (Puslit Oceanologi LIPI). Green Peace (2011) melaporkan bahwa ekosistem padang lamun mencakup luas sekitar $30.000 \mathrm{~km} 2$, dengan memiliki jumlah spesies sebanyak 13 buah, dimana sebesar $17,1 \%$ terlindungi, sedang sisanya belum. Ekosistem mangrove meliputi luas 3.244.018 Ha (Bakosurtanal), jumlah spesies adalah 45 buah (Spalding, dkk, 2002). Ekosistem mangrove yang terlindungi sebesar 21,97\% (Kementerian Kehutanan)

Di bidang perikanan jumlah tenaga kerja yang terkait langsung dengan perikanan - 2.265.213. Tahun 2011 jumlah kapal 581.845 buah. Tiga provinsi dengan jumlah kapal terbanyak : Sulawesi, Sumatera dan Jawa. Jumlah alat penangkap ikan 1.001.667 unit. Spesies Penyu 6 buah, 95 tempat kembang biak, $49 \%$ tempat kembang biak terlindungi (Kementerian Kehutanan). Spesies Dugong : 28 Habitat, 45\% habitat terlindungi (Kementerian Kehutanan). Kemampuan inventarisasi kekayaan lam laut tersebut perlu ditingatkan dengan program dan pendanaan yang memadai. Kegiatan riset yang dilengkapi dengan kemampuan teknologi yang memadai perlu ditingkatkan. Survei hidrografi, terrestrial, dengan dibantu dengan TIG perlu memperoleh perhatian yang memadai.

\section{G. Perencanaan Pengembangan Wilayah}

Evaluasi struktur tataruang dapat dilakukan dengan membandingkan pemetaan penggunaan lahan aktual dengan peta tataruang tersedia, yang bermanfaat bagi monitoring dan pengendalian penggunaan lahan. Fakta menunjukan bahwa alih fungsi lahan dari kawasan vegetatif menjadi kawasan terbangun, semakin sulit dikendalikan, terutama di Jawa. Satu contoh aplikasi data penginderaan jauh untuk perencanaan pengembangan wilayah adalah model penyediaan hutan kota, meliputi kegiatan-kegiatan: pemetaan, monitoring, dan perencanaannya.

\section{H. Peningkatan Kewaspadaan dari Berbagai Ancaman}

Negeri ini, dikaruniai tanah yang subur, kaya sumberdaya alam, lahan, air, hutan, mineral dan batuan, dan laut yang berpotensi untuk mensejahterakan rakyatnya. Tetapi kenyataannya, fakta tidak sama dengan harapan, pengelolaan sumberdaya yang tidak proporsional, telah menjadikan bangsa ini menjadi bangsa yang banyak tergantung pada bangsa-bangsa lain. Selain ketergantungan tersebut, derita dari bencana alam juga dating silih berganti. Masih terbayang di pelupuk mata, bencana gempa bumi dan tsunami di Aceh, 26 Desember 2004, 9,8 SR, yang menelan korban >300.000 jiwa; yang diikuti dengan gempa bumi Yogyakarta 27 Mei 2006, dengan korban 6000 jiwa, dan bencana-bencana alam lainnya (tanah longsor, banjir, kebakaran hutan dan hujan asap, kekeringan, angin ribut) yang silih berganti, serasa tiada henti-hentinya.

Penebangan hutan, >1,2 juta Ha per tahun, ekploitasi sumber-sumber air, mineral dan minyak bumi, yang tidak proporsinal, over fishing di berbagai perairan karena racun, bom dan praktek-2 menyimpang lainnya, alih fungsi lahan yang terus berlanjut, polusi, merupakan ancaman laten 
terhadap perubahan-perubahan iklim yang mengancam kehidupan kini dan yang akan dating.

Kita wajib bersyukur, karena bencana, telah memunculkan kesadaran bahwa kehidupan kita sebenarnya bersanding dengan bencana. Hal itu lambat laun diharapkan makin dapat diterima sebagai suatu Rahmat oleh seluruh masyarakat, yang pada gilirannya dapat mengantisipasi dengan pemahaman, pemaknaan dan adaptasi yang baik, dalam meraih kehidupan tentram lahir batin. Usaha-usaha untuk membantu para korban, untuk publikasi, penyadaran, rehabilitasi dan rekontruksi daerah bencana, telah dirintis dan dilakukan oleh para relawan, donator dan seluruh lapisan masyarakat, dengan tiada kenal lelah dan putus asa.

Ancaman yang memperlemah bangsa ini, juga dapat berasal dari luar negeri. Indonesia, dengan penduduk lebih dari 240 juta, sangat menakutkan para Negara tetangga kita, apabila Indonesia menjadi Negara adidaya, yang kuat ekonomi dan militernya. Olehkarena itu, melalui globalisasi dan berbagai strategi, usaha-usaha merongrong kedaulatan Negara terus menerus berlangsung. Fakta-fakta yang terjadi, seperti lepasnya Ligitan-Sipadan, Timor Timur, pengambilan pasir di Pulau-pulau kecil, konflik Poso, Ambon, Papua, Aceh, penggembosan industri dalam negri, bukan tidak mungkin bahwa itu semua adalah terkait dengan ancaman-ancaman terhadap kejayaan RI. Olehkarena itu, sudah saatnya, berbagai macam bentuk disaster yang mungkin melanda negeri ini perlu dicarikan penangkalnya.

\section{Pendetilan Data guna Penaggulangan Kemiskinan}

Disertasi Wahyu Widayat, 2008, tentang penggunaan SIG untuk pendetilan data kemiskinan di Indonesia, mampu menunjukan peningkatan efisiensi berbagai cara penanggulangan kemiskinan. Daerah studi di Brebes untuk level Kabupaten, alokasi bantuan kemiskinan dibuat sesuai nama, alamat, dengan satuan pemetaan berupa rumah mukim. Cara ini diyakini mampu mendukung progam Bantuan Langsung Tunai (BLT) dan evaluasi yang overlap dengan berbagai program penanggulangan kemiskinan. Pendataan jumlah rumah pernah dilakukan oleh Fakultas Geografi UGM (2006) ketika terjadi gempa bumi di Bantul. Citra Ikonos mampu menunjukan rumah-rumah yang ditimpa bencana, dalam kondisi rusak berat, rusak sedang, dan rusak ringan, sehingga bentuk bantuan renovasinya untuk masing-masing kategori dapat dibantu dengan data tersebut.

\section{J. Kontrol terhadap Penggunaan Lahan}

Pada masyarakat agraris, kesuburan tanah sebagai faktor kunci dalam penggunaan lahan, sedang dalam masyarakat industri dan jasa, faktor aksesibilitas sebagai faktor penentu. Alih fungsi lahan dapat dimonitor secara real time, bila telah dibangun geodatabase yang lengkap. Berbagai model alokasi lahan dapat dibuat untuk berbagai peruntukannya. Ketetapan tentang prosentase luas area fungsional kota dari Dirjen Cipta Karya, dimana kelestarian taman dan jalur hijau (15\%), dan lingkungan alam yang belum dimanfaatkan $(23,5 \%)$. Monitoring secara konsisten terhadap bentuk spasial penggunaan lahan dapat ditindaklanjuti dengan berbagai aktivitas pengendalian, dan pemeliharaan dan penegakan hukum, bila diketahui adanya penyimpanganpenyimpangan.

\section{K. Manfaat di Bidang Pendidikan}

Pemanfaatan SIG untuk pemetaan sumberdaya mineral Marilah kita meniru bangsa Jepang, ketika bangsa tersebut terpuruk karena bom atom yang dijatuhkan oleh Sekutu di Hiroshima dan Nagasaki, maka kebangkitan negara tersebut bertumpu pada pendidikan. Bangsa kita, saat ini dapat dikatakan sedang sakit parah, baik sakit secara fisik (degradasi Daerah Aliran Sungai, dan Linkungan) maupun sakit secara nir fisik (mewabahnya korupsi, penyakit, kemrosotan moral dan etika, disintegrasi aspirasi dan nilainilai kebangsaan). Analisis geografi perlu diberdayakan guna menyumbangkan perannya dalam mencerdaskan kehidupan bangsa, melalui data dan informasi spasial geografis pada berbagai lini pendidikan.

Data dan informasi sumberdaya, lingkungan, kerusakan lingkungan, akibat bencana, fenomena kerusakan lahan, kebakaran hutan, alih fungsi lahan dan global change yang dikemas dengan baik merupakan bahan ajar yang amat berguna bagi anak didik. Penyajian gambaran muka bumi (sungai, gunung, ngarai, danau, kota, desa, hutan, perkebunan) melalui foto udara, citra satelit 2 dan 3 dimensi amat membantu pemahaman tentang sumberdaya dan lingkungan yang baik dan subur dan yang mengalami kkerusaan. Bentuk penyajian dapat dalam bentuk denah, maket, poster, peta, peta foto, ortofoto, spasiomap, dan tayangan multimedia statik dan dinamik, akan meningkatkan pemahaman kondisi sumberdaya dan lingkungan dan pada gilirannya akan menumbuhkan rasa cinta tanah air. Ini merupakan perekat rasa persatuan dan dapat mencegah disintergrasi bangsa. Produk teknologi informasi geografi ini menggambarkan potensi dan kemungkinan bencana yang terjadi. Di Belanda, foto udara digunakan untuk mengenal medan bagi anak sekolah dasar. Di Perancis, peta topografi skala 1;5000 dijual bebas di toko alat tulis dan toko buku. Di Fakultas Geografi UGM kini telah terbentuk Pusat Pelayanan Informasi Kebumian, sebagai outlet Bakosurtanal dan instansi lain.

\section{KECERDASAN SPASIAL DALAM GEOGRAFI}

Kompetensi pendidikan geografi pada tingkat sekolah menengah, menurut Depdiknas (2003) memiliki ramburambu pendidikan : pembelajaran Geografi memperhatikan aspek keruangan, kelingkungan dan kompleks wilayah. Pengorganisasian materi dimulai dari pengenalan fenomena geografis dengan memanfaatkan bentang alam sekitarnya sebagai sumber informasi geografis. Bersamaan dengan kemajuan teknologi informasi, Geografi mengembangkan sistem informasi dari yang konvensional ke dalam penyajian mutakhir dalam bentuk teknologi sistem informasi geografis, sebagai bagian dari Sains Informasi Geografi. Siswa diharapkan secara bertahap melakukan penyesuaian dalam penyajian informasi geografis mulai dari mendeskripsi ulang dan menggambar ulang dengan bantuan 
berbagai alat sehingga mampu menuangkan gagasan dalam bentuk peraga. Bagi pendidikan di atasnya, para mahasiswa, dasar pemahaman tersebut tidak jauh berbeda, namun tentunya lebih mendalam dan lebih tinggi.

Kecerdasan spasial dalam geografi dapat dilakukan dengan melalui : (1) Spatial Association : Suatu fenomena di muka bumi terdistribusi secara bersamaan; (2) Spatial Interaction : Dinamika proses pergerakan penduduk suatu lokasi ke lokasi yang lain, (3) Spatial Diffusion : Proses perpindahan ide dan inovasi antara individu dan kelompok di suatu wilayah, (4) Spatial Perspective : Konsep penentuan lokasi tempat manusia hidup dan berintraksi satu sama lain.

Contoh aplikasi Penginderaan Jauh dan SIGs dalam penerapan pendekatan spasial untuk pendidikan geografi antara lain (1) identifikasi langsung obyek geografi pada citra dan peta, (2) menghitung luas dan menyajikan sebarannya, (3) memahami kerja SIG secara teknis, (4) membuat gambar, tabel, diagram, peta dengan SIG, (5) analisis potensi sumberdaya dan lingkungan, (6) penyusunan atlas.

Identifikasi langsung obyek geografi sebagai proses membaca dan analisis spasial obyek geografi dapat dilakukan pada citra dan peta, baik melaui produk statik maupun dinamik. Tingkat kesulitan identifikasi tersebut adalah (1) penggunaan lahan/liputan lahan, vegetasi, hutan, (2) hidrologi, geologi, geomorfologi, (3) tanah, (4) laut, (5) Fenomena sosial ekonomi, budaya penduduk. Produk dari citra dapat berupa photomap, spasiomap, orthofoto, peta dasar, peta tematik yang kesemuanya mudah menyajikan data luas dan persebarannya dengan teliiti. Semua lini pendidikan perlu ketrampilan dalam melakukan ekstraksi informasi ini, agar data yang diperoleh dapat membantu analisis spasial geografi.

Kerja SIG seperti halnya sistem komputer yang lain, memerlukan ketrampilan khusus, yang harus memiliki pengetahuan tentang hardware, software, data dan standart operation dalam sistem informasi. Tersedia 3 tingkatan dalam kerja ini : operator, analis, manager. Pendidikan sampai dengan tingkat diploma, sebaiknya diarahkan pada skill ketrampilan pada level operator. Pendidikan jenjang $\mathrm{S} 1$, diorientasikan sebagai analis.

Gambar berupa peta, tabel, diagram, tampilan visualisasi multimedia dapat disajikan dengan SIG, baik statik maupun dinamik. Presentasi spasial obyek geografi dapat diujutkan dengan baik melalui perangkat ini. Untuk itu memerlukan ketrampilan yang perlu dilatih dengan teratur. Pembangunan laboratorium SIG merupakan langkah yang tepat di semua lini pendidikan geografi yang membutuhkan. Agar mampu menganalisis potensi sumberdaya, maka pengetahuan tentang sumberdaya tersebut harus dikuasai. Analisis potensi sumberdaya lahan harus menguasai ilmu tanah, geomorfologi, pedologi dan edafologi. Analisis potensi sumberdaya air harus menguasai dan paham hidrologi, geohidrologi, meteorologi, klimatologi, dan kriologi. Analisis potensi sumberdaya hutan harus paham ilmu kehutanan, botani, biologi. Analisis potensi sumberdaya mineral dan batuan harus mahis dalam ilmu geologi, geofisika, pertambangan, seismografi. Analisis potensi sumberdaya laut harus menguasai oceanografi, oceanografi, klimatologi. Melalui produk geospasial, pemahaman ilmuilmu tersebut makin mudah.

Data dan informasi sumberdaya dan lingkungan yang dikemas dengan baik dalam bentuk atlas, merupakan bahan ajar yang amat berguna pengguna. Penyajian gambaran muka bumi (sungai, gunung, ngarai, danau, kota, desa, hutan, perkebunan) melalui foto udara, citra satelit 2 dan 3 dimensi dikemas dalam atlas manual dan digital, amat membantu pemahaman tentang sumberdaya dan lingkungan. Selain berbentuk atlas, bentuk penyajian data spasial tersebut dapat berbentuk denah, maket, poster, peta, peta foto, ortofoto, spasiomap, dan tayangan multimedia statik dan dinamik. Produk tersebut dapat meningkatkan pemahaman tentang sumberdaya dan lingkungan dan pada gilirannya akan dapat menumbuhkan rasa cinta tanah air. Hal ini merupakan perekat rasa persatuan dan dapat berpengaruh dalam mencegah disintergrasi bangsa.

\section{PERAN PENGINDERAAN JAUH DAN SIG UNTUK MITIGASI BENCANA}

SIG, sebagai sains dilengkapi dengan sistem informasi yang dirancang pelaksanaannya dengan mendasarkan pada letak spasial atau koordinat geografi. Dengan kata lain, SIG merupakan suatu sistem "data base" yang memiliki kemampuan tertentu untuk data yang bereferensi spasial dan juga merupakan serangkaian proses kerja dengan data spasial dan atribut. Star and Estes (1990, dengan perubahan) menyatakan bahwa pemahaman terhadap lingkungan alam dan gejala-gejalanya (termasuk bencana alam) dapat dilakukan dengan menerapkan konsep 5M. Lima $\mathrm{M}$ tersebut adalah pengukuran (measurement), pemetaan (mapping), pantauan (monitoring), pembuatan model spasial (modeling), dan pengelolaan (management). Data penginderaan jauh merupakan input penting pada SIG karena datanya muthakir, lengkap dan cepat diperoleh

Agar supaya suatu lembaga dapat melaksanakan kegiatan pengelolaan wilayah untuk mengatasi dampak bencana, maka sebuah intutusi pengelolaan data amat diperlukan. Penyusunan institusi tersebut memerlukan tersedianya hardware, software, data spasial dan numerik, sumberdaya manusia, prosedur kerja standart, dan mekanisme pendukung. Pengembangan institusi semacam ini memerlukan pemantapan tujuan, dukungan dana, sumberdaya manusia (teknisi, analis, pengelola), spasial information expert, application GIS expert dan perlu berhubungan dengan para vendor.

Aplikasi data geospasial untuk bencana alam meliputi kegiatan-kegiatan berikut: identifikasi, pemetaan, monitoring dan pemodelan (modeling) kejadian bencana alam. Secara ringkas, berikut ini disajikan bidang bencana alam yang dapat dibantu oleh teknik penginderaan jauh.

\section{A. Identifikasi Kejadian Bencana Alam}

Kejadian bencana alam yang dapat diidentifikasi dengan data penginderaan jauh antara lain adalah genangan banjir, aktivitas volkanik, longsor lahan, kebakaran hutan, kekeringan (desertifikasi), angin ribut/badai. 
Identifikasi genangan banjir dilakukan pada citra penginderaan jauh spektrum biru, inframerah dan microwave. Pada spektrum biru selain luas genangan, kedalaman genangan dapat diinterpretasikan. Pada inframerah, batas lahan genangan dan lahan kering sangat tegas disajikan, sehingga delineasi daerah yang terkena bencana dan yang tidak dapat dilakukan. Turbulensi genangan (tenang, berolak) dapat dilacak pada citra yang direkam dengan gelombang mikro, misalnya pada band $\mathrm{C}$ $(3,25 \mathrm{~cm})$. Dengan pengamatan ini, besar/kecilnya bencana banjir yang timbul dapat diestimasikan.

Aktivitas volkanik (letusan gunung api, aliran lava, lahar, debu volkanik) dapat dikenali pada citra visible, pankromatik. Aliran lava panas ditafsirkan dengan menggunakan citra thermal, demikian pula pengenalan kebakaran hutan, melalui hot spot.

Longsor lahan (slide, fall, subsience, creep) dikenali pada citra penginderaan jauh dengan pendekatan melalui rona, bentuk, situs, pola pada citra pankromatik, maupun inframerah. Bentuk yang khas pada situs berbukit, bergunung terutama pada perubahan lereng memungkinkan dijumpai bentuk longsor lahan. Hujan dan drainage menentukan terjadinya hal ini.

Kekeringan lahan dapat dipelajari dengan NDVI (Normalized Difference Vegetation Index), akibat dari penebangan hutan, melalui kajian perubahan pertumbuhan hutan dengan analisis data multispektral dan multitemporal. Skala besar lebih baik dibandingkan skala kecil dalam identifikasi obyek bencana alam tersebut.

\section{B. Pemetaan Bencana Alam}

Dalam pemetaan genangan banjir, aktivitas volkanik, longsor lahan, kebakaran hutan, kekeringan (desertifikasi) perlu diperoleh data mengenai jenis, luas per jenis, distribusi dan penyebaran, serta kondisi dan kualitas bencana alam tersebut.

Teknik multitingkat (multistage) dan multispektral dapat digunakan untuk dan pemetaan. Pada teknik multitingkat, pengolahan citra diawali dengan citra satelit yang cakupannya luas, kemudian dilanjutkan dengan interpretasi foto udara skala kecil/sedang; skala besar dan diakhiri dengan survey lapangan. Makin besar skala citra yang digunakan daerah cakupan makin sempit. Pada teknik multispektral digunakan citra berbagai band agar pengenalan obyek bencana alam yang berbeda kondisinya (sehat/tidak; subur/tidak) menjadi lebih baik. Langkahlangkah pemetaan kejadian bencana alam (lokasi bencana, dan daerah pengaruh bencana) sebagai berikut :

1. Pengadaan citra, penyusunan mozaik, pembuatan citra terkoreksi, identifikasi daerah bencana

2. Orientasi lapangan (melalui darat atau udara)

3. Interpretasi obyek bencana alam (deteksi, identifikasi, delineasi), yang dibantu dengan sistem klasifikasi bencana alam, rujukan tambahan, pengetahuan tentang daerah bencana. Hasil interpretasi tergantung dari kemahiran interpreter. Delineasi dilakukan secara manual, digital atau interaktif.
4. Penyusunan peta tentatif bencana alam, dilengkapi legenda dan deskripsi hasil interpretasi

5. Tinjauan lapangan pada lokasi sample, untuk meyakinkan, menambah, koreksi hasil interpretasi. Alat GPS, peta topografi, peta tentatif bencana diperlukan untuk penetapan lokasi dan kondisi bencana alam.

6. Interpretasi ulang, koreksi dan konfirmasi

7. Penyajian peta bencana alam, sesuai skala yang akan dibuat, dilengkapi dengan laporan.

\section{Monitoring Daerah Bencana Alam}

Monitoring bencana alam adalah pemetaan bencana alam dengan waktu yang berbeda-beda, yang dimungkinkan oleh adanya resolusi temporal pada penginderaan jauh (16, 26, 5 hari atau $12 \mathrm{jam})$. Hasil berbagai pmetaan dengan beda tanggal tersebut disusun dalam suatu basis data bencana alam. Dengan melakukan hal tersebut maka perubahanperubahan yang terjadi dalam daerah bencana alam (luas, intensitas, distribusi dan penyebaran, akibat bencana, kondisi lingkungan) dapat diketahui. Pengujian lapangan secara selektif dapat menambah informasi tentang perubahan hutan, khususnya tentang intensitas perubahan dan penyebabnya. Secara digital, hal ini lebih leluasa dilakukan, walaupun secara manual juga memungkinkan.

\section{Evaluasi Daerah Bencana Alam}

Data kondisi bencana alam bersama-sama dengan informasi pendukung kejadian bencana alam, dapat digunakan untuk evaluasi daerah bencana alam, yang diujutkan alam bentuk (1) peta kerentanan terhadap bencana alam, (2) peta daerah bahaya dan analisis besarnya korban, (3) peta rencana pengelolaan daerah bencana alam, (4) kebijakan-kebijakan terkait pengelolaan bencana. Contoh evaluasi ini misalnya : evaluasi untuk menilai rentan daerah terhadap kebakaran hutan, kerusakan bencana longsor lahan, banjir. Dalam hal ini, model evaluasi dan algoritma khusus diperlukan untuk setiap tujuan yang berbeda.

\section{E. Peramalan Kejadian Bencana Alam}

Pengamatan data bencana alam yang terus menerus, yang telah membentuk basisdata bencana alam, dapat digunakan untuk peramalan kejadian bencana alam dan memperkirakan trend, periode ulang, dsb. Kondisi daerah bencana yang makin membaik atau memburuk ditinjau dari luas bencana, intensitas bencana, akibat bencana, perlu disikapi dengan persiapan yang sebaik-baiknya agar dapat meminimalkan dampak bencana.

\section{F. Studi Bencana Alam}

Berbagai bencana alam (banjir, longsor, letusan gunung api, gempa, tsunami, hama belalang) yang terjadi mengharuskan lembaga yang kompeten untuk melakukan upaya terkait penanggulangan bencana alam (Bakornas PB, SAR, Mawil Hansip). Bekerjasama dengan perguruan tinggi (UGM) dan luar negri dibentuk sistem informasi 
penanggulangan bencana alam (SIPBI). Kinerja utamanya adalah penyusunan basisdata wilayah untuk mitigasi bencana : pemetaan daerah bencana, evaluasi bencana, kajian evakuasi, Early warning System. Kejadian bencana alam yang dapat diidentifikasi dengan data penginderaan jauh antara lain adalah genangan banjir, aktivitas volkanik, longsor lahan, kebakaran hutan, kekeringan (desertifikasi), angin ribut/badai.

Identifikasi genangan banjir, aktivitas volkanik (letusan gunung api, aliran lava, lahar, debu volkanik), Longsor lahan (slide, fall, subsience, creep), kekeringan lahan dapat dipelajari dengan berbagai citra turunan hasil trannsformasi matematis. Selain hal itu, tumpahan minyak mentah yang menyebabkan polusi, menghasilkan kajian-kajian tentang Indeks Kepekaan lingkungan, yang bermanfaat bagi penilaian dampak lingkungan dan kompensasi kerugian dan kerusakan lingkungan. Contoh tentang hal ini dapat dijumpai di Samarinda, Cilacap.

Tumpahan minyak di laut berbahaya bagi lingkungan. Polusi terhadap air tanah sangat berbahaya bagi penduduk. Buangan tailing dari eksploitasi pertambangan dengan kandungan logam berat $(\mathrm{Hg}, \mathrm{Cd}, \ldots)$, merupakan bom waktu bagi penduduk. Reklamasi wilayah pantai oleh negara tetangga, perlu diwaspadai, krn dapat digunakan sebagai tipu muslihat yang mengurangi wilayah NKRI dan menggeser maritime boundary.

Kajian tentang Kenyamanan Lingkungan dapat dilakukan dengan formula berikut : IK $=0,8 \mathrm{~T}+(\mathrm{RH} \times \mathrm{T}) / 500$, dimana IK : indeks kenyamanan; $\mathrm{T}$ : temperatur derajat Celcius; $\mathrm{RH}$ : kelembapan relatif. Nilai IK disebut nyaman bila berkisar antara 25 - 27. T dapat diperoleh dari citra thermal $(2,5-3,5$ dan 10 - 12,5 um) pada citra Landsat TM band 6 atau citra NOAA band 4 dan band 5 .

Kejadian Luar Biasa (KLB) adalah merebaknya wabah penyakit yang secara endemik tiba-tiba menyerang suatu daerah. Akhir-akhir ini tercatat malaria, demam berdarah dengue, cikungunya, dilaporkan telah meledak dimana-mana dengan vektor pembawa penyakitnya adalah nyamuk. Hal ini memotivasi ahli toksikologi bekerjasama dengan pakar geografi, untuk mempelajari habitat nyamuk, dan menentukan tingkat kerawanan suatu daerah terhadap terjadinya KLB tersebut. Di UGM, kelompok ini membentuk Pokja Inderajakes (Kelompok Kerja Penginderaan Jauh untuk Kesehatan) sejak 1997, dipimpin oleh Prof. Dr. Sugeng Yowono Mardihusodo, Fakultas Kedokteran UGM dan penulis.

\section{G. Pendidikan Kebencanaan}

Pendidikan kebencanaan memberikan kemampuan untuk memahami terminology dalam menagemen bencana; mampu menjelaskan perbedaan disaster preparedness, mitigation, prevention and response; memiliki kemampuan untuk meneguhkan konsep kebencanaan melalui pendidikan, penguatan kapasitas dan kerentanan individu dan masyarakat. Pengertian prevention adalah mampu menghindari dampak bahaya/bencana. Mitigation mencakup pembelajaran dan pengurangan dampak bahaya/bencana. Preparedness mencakup pengetahuan dan kemampuan secara efektif untuk antisipasi, respond an memperbaiki dampak bencana. Risk Reduction berisi pengertian pengurangan risiko melalui usaha sistematis untuk analisis dan mengelola penyebab bencana : mengurangi kerentanan, meningkatkan antisipsi dampak bencana. Response merupakan tindak darurat penyelamatan kehidupan dan memenuhi kebutuhan hidup. Pendidikan bencana melalui analisis dan kecerdasan spasial diarahkan agar para geograf memiliki :

1. pemahaman tentang konsep pengelolaan risiko bencana

2. kemampuan membangun standart kesiapsiagaan, mitigasi, dan persiapan serta tanggap darurat

3. pemahaman pengurangan risiko bencana melalui pendidikan dan pelatihan serta menguatkan perencanaan pembelajaran, koordinasi, partisipasi masyarakat, intersektoral.

4. Kemampuan menerapkan pengetahuan, hasil belajar dan contoh sukses untuk memperkuat program dan pelaksanaan program kebencanaan.

5. Pemahaman tentang proses dan produk siklus bencana serta mampu menyesuaikan secara holistic, melalui pendidikan managemen siklus kebencanan yang berkualitas, yang meliputi : response, recovery, preparedness, mitigation and prevention

\section{PEMBANGUNAN BERKELANJUTAN BLUE ECONOMY}

Pembangunan berkelanjtan sangat penting diterapkan di Indonesia, karena prinsip pembangunan ini sesuai dengan tujuan bangsa Indonesia, yaitu tercappainya msyarakat adil makmur. Pembangunan berkelanjutan menggunakan prinsip ekologis (alam adalah titipan dari anak cucu, sehingga jangan dirusak); prinsip ekonomi (meningkatkan daya beli rakyat), prinsip sosial (adil bagi seluruh rakyat Indonesia). Peran geografi dalam konsep ini sangat nyata, baik pada pemahaman ekologis, maupun pada kriteria yang lainnya. Sejak dulu diawal pembangunan, kita mengenal usaha untuk meraih kesejahteraan rakyat dengan cara eksploitasi SDA terutama hasil tambang minyak dan batuan (coklat); kemudian kesejahteraan beralih bertumpu ke arah hutan (hijau), dan kini usaha tersebut mendasarkan pada konsep ekonomi biru (blue economy), yang dicetuskan oleh Gunter Poly.

Sunoto (2013) mengemukakan bahwa esensi dari konsep tersebut adalah : "Pembangunan berkelanjutan adalah pembangunan yang memenuhi kebutuhan masa kini tanpa mengurangi kemampuan generasi mendatang untuk memenuhi kebutuhan mereka sendiri': tidak merusak sistem alam : atmosfir, air, tanah, dan makhluk hidup -mengurangi pencemaran dan kerusakan lingkungan, mengendalikan eksploitasi sumberdaya alam. Rumusan pembangunan berkelanjutan adalah suatu proses perubahan yang mana eksploitasi sumberdaya, arah investasi, orientasi pengembangan teknologi, dan perubahan kelembagaan semuanya dalam keadaan yang selaras, serta meningkatkan potensi masa kini dan masa depan untuk memenuhi kebutuhan dan aspirasi manusia." (Brundtland Commission, 
1987, dalam Sunoto, 2013). Blue Economy mencontoh alam, yaitu cara kerja ekosistem bekerja sesuai dengan apa yang disediakan alam dengan efisien: tidak mengurangi tapi justru memperkaya alam.

Cara kerja ekosistem dijadikan model Blue Economy, yaitu seperti air mengalir dari gunung membawa nutrien dan energi untuk memenuhi kebutuhan dasar kehidupan seluruh makhluk hidup dan tanaman. Limbah dari sesuatu menjadi makanan bagi yang lain, limbah dari satu proses menjadi bahan baku/sumber energi bagi yang lain. Hanya dengan gravitasi, energi didistribusikan secara efisien dan merata tanpa ekstraksi energi eksternal. Ekosistem selalu bekerja menuju tingkat efisiensi lebih tinggi untuk mengalirkan nutrien dan energi tanpa limbah untuk memenuhi kebutuhan dasar bagi semua kontributor.

Keberlanjutan diraih dengan efisiensi sumberdaya alam, tanpa limbah - tidak ada sisa untuk limbah: limbah dari satu proses menjadi bahan baku dari proses produksi yang lain, kepedulian sosial: lebih banyak hasil-lebih banyak penyerapan tenaga kerja-lebih banyak peluang bagi orang miskin, sistem produksi siklus (non linier) dengan prinsip generasi dan regerasi inovasi tanpa batas. Prinsip konsep ini adalah (1) meningkatkan efisiensi SDA dan nilai ekonomi untuk kesejahteraan masyarakat, (2) meningkatkan aktivitas ekonomi dengan konsep pembangunan berkelanjutan, (3) meningkatkan aksesibilitas masyarakat lokal terhadap sumberdaya ekonomi, (4) mendorong berkembangnya investasi inovatif dan kreatif untuk peningkatan efisiensi dan nilai tambah sumberdaya alam, (5) mengembangkan system pengelolaan SDA secara seimbang antara pemanfaatan dan pelestarian lingkungan

Konsep ini, produksi tanpa limbah, nampaknya sesuai dengan harapan kita, pembangunan yang ramah ingkungan, efisien resources dan memberdayakan rakyat banyak, rantai produksi melibatkan banyak orang, menuju sejahtera.

\section{KESIMPULAN}

Geografi sebagai cabang ilmu yang sudah mapan, telah terbukti kemantapan konsep, pengertian, pendekatan, analisis dan aplikasinya bagi pembangunan di Indonesia. Peran geografi tersebut antara lain, selain sebagai salah unsur pembentuk negara, juga mendukung ketahanan pangan, energi, dan wilayah. Pada era pertanian pangan berasal dari usaha pertanian, dan energi dari hasil tambang. Manfaat lainnya adalah mempelajari keberadaan sumberdaya alam, manusia dan buatan, mendukung perencanaan, implementasi, monitoring dan evaluasi pelaksanaan pembangunan nasional serta menumbuhkan rasa cinta tanah air.

Teknologi Informasi Geografi, penghasil data geospasial semakin berkembang dalam hal teknik dan aplikasinya dalam mendukung pelaksanaan kegiatan pembangunan nasional. Peran tersebut nampak dalam penerapannya di berbagai kementerian dan lembaga, yang menggunakan bumi sebagai obyeknya. Di Indonesia, pembangunan nasional terdukung oleh geografi, baik pada obyek, pendekatan maupun terapannya. Kajian bencana alam baik berupa longsorlahan, banjir, kekeringan, kebakaran hutan, dan bencana lainnya (tsunami, gempa bumi), mitigasi bencana alam, diinisiasi oleh para ahli geografi, dan hal ini menguatkan peran geograf. Pemulihan lingkungan yang mengalami kerusakan memerlukan data geospasial yang dikelola dengan dalam SIG dan sistem pendukung lainnya.

Aplikasi geografi dalam pembangunan antara lain meliputi 12 butir (basisdata, kajian sumberdaya alam, lingkungan, ancaman, pendidikan,...) menunjukan peran nyata geografi untuk pembangunan. Menuju kelestarian lingkungan dan pemanfaatan sumberdaya, konsep blue economy, yang bertumpu pada pemanfaatan resources yang efisien dan meminimalisir limbah, perlu diintrodusir dan diterapkan dengan baik, agar tercapai kelestarian alam dan dapat mensejahterakan rakyat.

Analisis geografi membutuhkan kecerdasan spasial dalam merumuskan dan memanfaatkan data geospasial. Kecerdasan spasial ini penting untuk pendidikan bencana bagi geograf agar mampu menelaah dan memanfaatkan teknologi informasi geografi guna pengelolaan bencana (response, recovery, preparedness, mitigation and prevention). Pengelolaan bencana alam memerlukan basisdata lingkungan, kejadian bencana, dampak bencana dan data sarana prasarana pendukung, yang antara lain dapat diperoleh dari analisis citra penginderaan jauh (foto udara, radar hingga citra satelit), yang dilengkapi dengan survey dan uji medan. Setiap jenis citra penginderaan jauh, dicirikan dengan sifat spasial, spektral dan temporal memiliki peran yang khas terhadap perolehan data lingkungan, termasuk kejadian bencana alam guna pengelolaannya. Pembentukan basisdata kebencanaan perlu dilakukan dalam penanganan bencana alam. Dalam hal ini diperlukan hardware, software, data spasial dan numerik, sumberdaya manusia, prosedur kerja standart, dan mekanisme pendukung.

\section{PUSTAKA}

Asadi, H.H. 2000, The Zarshuran Gold Deposit Model Applied in a Mineral Exploration GIS in Iran. Disertation. Delft University of Technology

Anonim, Program Pembangunan Nasional 2000-2004, UU Nomor 25 tahun2000. Pemerintah Republik Indonesia

Agus Siswanto, 2008, Pemetaan Hutan mangrove di Kepulauan Karimunjawa, Dengan metode Berlapis, Skripsi, di Fakultas Geografi UGM.

Antenucci, John C, Kay Brown, Peter L. Croswell, Michael J. Kevany, Hugh Archer, 1991, GIS a Guide to the Technology, New York, van Nostrand Reinhold

Belward Alan, S dan Carlos R. Valenzuela, 1991, Remote Sensing and GIS for resource Management in Developing Countries, Enschede, Kluwer Academic Publishers

Dangermond, Jack, 2011, Geography: A Platform for Understanding, ESRISeminar.

DeMers, Michael N, 1997, Fundamentals of GIS, New York, John WIley and Sons, Inc.

Dulbahri, 1994, Kajian Air Tanah di DAS Progo Dengan Menggunakan Citra Penginderaan Jauh. Disertasi. UGM Yogyakarta

Eddy Prahasta, 2002, Konsep-Konsep Dasar Sistem Informasi Geografi, InformatikaBandung

Hagget, Peter, 1978, Geography : the Modern Syntesis, McGrawHill Book, New York 
Hartono, 2003, Aplikasi Penginderaan Jauh untuk Hutan Kota, DiktatPelatihan diselenggarakan oleh Fakultas Kehutanan UGM.

Hartono, 2010, Penginderaan jauh dan SIG serta Aplikasinya di BidangPendidikan dan Pembangunan, Paper disajikan pada Seminar Nasional, dengan tema Pemanfaatan Penginderaan Jauh dan Sistem Informasi Geografis untuk Pembelajaran Geografi dan Pembangunan Nasional, Fakultas Geografi Universitas Muhammadiyah Surakarta (UMS) pada tanggal 3 Juli 2010, di UMS Surakarta.

Hartono, 2014, Peranan Geografi untuk Pembangunan Nasional di Era Global, Paperdisajikan pada Mega Seminar Nasional dan Reuni Akbar, Geografi untukmu Negeri, diselenggarakan oleh Jurusan Pendidikan Geografi Fakultas Ilmu Sosial Universitas Negeri Yogyakarta, di Yogyakarta pada tanggal 5 Mei 2014.

Hartono, 2015, Pendidikan Geografi Di Era Global : Tinjauan Substantif di EraProgram Nawa Cita dan Issu Dunia, Paper disajikan pada kuliah umum di Jurusan Geografi Fakultas Ilmu Sosial Universitas Negeri Malang, Malang, pada tanggal 3 September 2015

Hartono, 2016, Peran Penginderaan Jauh dan Sains Informasi Geografi untukPendidikan Bencana, Paper disampaikan pada Kuliah Umum Mahasiswa S1 Prodi Pendidikan Geografi UMS, Surakarta pada tanggal 16 Desember 2016
JAFTA (1990), Pemetaan dan Registrasi Penggunaan lahan Hutan di PulauSumatera, Kerjasama antara Kementerian Kehutanan dan Japan Association Forest Technical Assisstance.

Projo Danoedoro, 1996, Pengolahan Citra Digital, Fakultas Geografi UGM.

Rusyidi, 2012, Disertasi, Fakultas Geografi UGM, Yogyakarta

Scholten, Henk J, GIS for Urban and Regional Planning, Dobdbrecht, Kluwer Academic Publishers.

Sriyono, 2010, Disertasi, Fakultas Geografi UGM, Yogyakarta

Sugeng Yuwono, 1997, Prosiding Seminar Penginderaan Jauh dan SIGuntuk Kesehatan, Yogyakarta, Fakultas Kedokteran UGM.

Sunoto, 2013, Pengembangan Pulau-Pulau Kecil Berkenjutan dengan konsepBlue Economy, disajikan dalam Seminar nasional Pengembangan Pulau-Pulau Kecil di Indonesia, diselenggarakan oleh Dirjjen P3K KKP, bekerjasama dengan Pemerintah Daerah Kabupaten Alor NTT, Kalabahi-Alor, 16 Agustus 2013.

Wahyu Widayat, 2008, Pendetilan Data Kemiskinan Menggunakan SIG gunaPenanggulangan Kemiskinan, disertasi UGM Yogyakarta

Windarti Irma, 2003, Kajian Kenyamanan Lingkungan Kota Yogyakarta, Thesis S2, Ilmu Lingkungan, UGM Yogyakarta 